\title{
Role of Aquaporins in Salt Tolerance of Common Sunflower
}

\author{
Solwan A. Hasan ${ }^{1 *}$, Sami H. Rabei ${ }^{1}$, Reham M. Nada ${ }^{1}$ and Gaber M. Abogadallah ${ }^{1}$ \\ ${ }^{1}$ Department of Botany, Faculty of Science, Damietta University, New Damietta 34517, Egypt.
}

Received: 19-03-2019/Accepted: 20-06-2019

*Corresponding author: selwan_hakam@du.edu.eg

\begin{abstract}
The present work is addressed photosynthetic rate, growth rates and quantification of aquaporin genes expression on sunflower plant to examine the expression and regulation profiles of some aquaporins, their role in regulating water transport during salt stress and their role in improving plant tolerance to stresses. The differential regulation of aquaporins might contribute to increased resistance/susceptibility to a specific stress, in a species-specific way. Aquaporins fine regulation helps plants maintain a positive water balance under detrimental environmental conditions. Both down- and up-regulation of aquaporin expression leading to changes in membrane permeability have been described and proposed to be beneficial for plants experiencing water deficit. Plants may decrease the water permeability of their cell membranes to avoid excessive loss of water from the root to the soil and / or aquaporins might play a role in stress avoidance by enhancing root water uptake, when the water potential gradient between soil and root xylem is still favorable. The contribution of both types of responses may depend on the plant species, the intensity and duration of the stress and aquaporin isoform. The salt tolerance is a complex trait but might be partly due to the expression of stress-inducible aquaporin isoforms. The plant shows different expression level of PIP1;5, PIP2;1, PIP2;3, TIP1;1 as well as different water transport activity..
\end{abstract}

Keywords: Aquaporin; gene expression; salinity; salt tolerance; sunflower.

\section{Introduction}

Salinity is an important factor that causes serious economic reduction in agriculture productivity worldwide. The excess presence of sodium ions in root growing zone and in irrigation or ground water has tremendous negative effects on the distribution of species in any given environment. Worldwide, it is estimated that salinity affects more than 800 million ha (Tester and Davenport, 2003). The response of plant to salinity stress occurs in two phases: a rapid response to the increase in external osmotic pressure, and a slower response due to the accumulation of $\mathrm{Na}^{+}$in leaves (Cramer 2002; Fricke and Peters 2002; Gilliham and Tester 2005).

Excess of $\mathrm{NaCl}$ in soil and irrigation water causes hyperosmotic and hyperionic stress effects, which if sufficiently severe can result in plant death (Bressan et al., 2008). The hyperosmotic effect results from concentration of extracellular solutes, which causes a flux of water out of the cell, a decrease in the osmotic potential within the cell, and in the cellular turgor pressure (Lichtenthaler, 1996). The hyperionic effect resulting from 
exposure to high salinity leads to "toxic sodium effect", whereby excess $\mathrm{Na}+$ in the cytoplasm causes an unbalance of other essential ions such as $\mathrm{K}+$ and $\mathrm{Ca}+$ (Bohnert and Jensen, 1996; Hasegawa et al., 2000). High concentration of $\mathrm{Na}+$ ion in the cytosol causes metabolic toxicity, in part due to the competition between $\mathrm{K}+$ and $\mathrm{Na}+$ for binding sites for several enzymes (Tester and Davenport, 2003).

Plants have the capacity to rapidly alter their cell and tissue hydraulic conductivity to control their water balance. Such mechanism is mostly achieved via the regulation of the abundance and activity of water channels in the cell membrane known as aquaporins (Chaumont and Tyerman 2015). Despite the relatively high water permeability of biological membranes, they contain water-selective channels which can facilitate and regulate the passage of water. Aquaporins belong to the ancient family of major intrinsic proteins (MIPs) which are small integral membrane proteins.

Aquaporins in plants are important in regulating water flow through the plant body and in maintaining cellular water homeostasis in all environmental conditions (Hachez et al., 2006b). However, aquaporins not only transport water but also represent important membrane-selective pathway for small-uncharged solutes, including glycerol, urea, ammonia, carbon dioxide, hydrogen peroxide, and the metalloids boric acid, silicic acid, and arsenite (Chaumont and Tyerman, 2015). These multifunctional channels are important not only in water homeostasis, but also in plant metabolism, nutrition, and signaling processes (Tyerman et al., 2002; Maurel et al., 2008; Gomes et al., 2009; Hachez and Chaumont, 2010; Ma, 2010; Miwa and Fujiwara, 2010; Bienert and Chaumont, 2011; Bienert and Chaumont, 2013; Kaldenhoff et al., 2013).

Aquaporins are tightly regulated at multiple levels to control their expression profile, trafficking, abundance and activity. These regulatory mechanisms therefore play an essential role in reversibly fine-tuning the plant hydraulic conductivity in response to external stimuli (Martinez-Ballesta et al., 2003; Boursiac et al., 2008; Postaire et al., 2010; Hachez et al., 2012; Prado et al., 2013). Many aquaporin isoforms show differential expression in response to abiotic stresses such as drought, salinity and cold, some being up-regulated while others get repressed (Sakurai et al., 2005; Zhu et al., 2005; Alexandersson et al., 2005).
Conflicting data regarding the transcriptional response of specific Arabidopsis PIP genes to salt stress were reported. In two week-old plants, Jang et al. (2004) found that salt exposure $(150 \mathrm{mM}$ $\mathrm{NaCl}$ ) triggers up-regulation of $P I P$ mRNA expression except for $P I P 1 ; 5$ in roots and $P I P 2 ; 6$ in leaves that were significantly down-regulated. Similarly, PIP2;7 (initially referred to as SaltInduced MIP (SIMIP)) was reported to be strongly up-regulated by short $(<6 \mathrm{~h}) \mathrm{NaCl}$ treatment $(150$ $\mathrm{mM} \mathrm{NaCl}$ ) in 8 day-old seedlings (Pih et al., 1999) and a twofold up-regulation was observed in 2 weekold seedlings by Jang et al. (2004).

However, other reports point to an opposite response of Plasma membrane intrinsic proteins (PIPs) to salt stress in Arabidopsis. Boursiac et al., (2005), Lee and Zwiazek, (2015) and MartinezBallesta et al., (2003) showed that exposure of Arabidopsis plants to salt (up to $100 \mathrm{mM}$ ) induces a general transcriptional down-regulation of PIPs. PIP2;7 gene expression is, in this case, repressed by salt treatment. Such transcriptional downregulation of PIP genes including PIP2;7 is also measured after drought stress (Alexandersson et al., 2010) or other abiotic stresses (Kilian et al., 2007) as detected in microarray data available on the eFP browser (Winter et al., 2007). It was proposed that PIP down-regulation might limit water loss and create a hydraulic signal that could induce stomatal closure (Jang et al., 2004; Boursiac et al., 2005).

Salt stress not only affects the transcriptional regulation of PIPS but also alters the abundance of PIP proteins in the Plasma membrane (PM) and their cycling between the PM and endosomal compartments including the trans-Golgi network and the early endosomes (TGN/EE) (Boursiac et al. 2005, 2008; Li et al. 2011; Luu et al. 2012; Hachez et al. 2014a). Dynamic changes in aquaporin subcellular localization were observed in osmotically challenged cells. For instance, mannitol-induced osmotic stress in ice plant suspension cells induces the relocalization of McTIP1;2 from the tonoplast to a putative endosomal compartment (Zhu et al., 1998). This process is dependent on aquaporin glycosylation and a cAMP-dependent pathway. In salt-treated Arabidopsis roots, AtTIP1;1, but not the AtTIP2;1 homolog, is relocalized in vacuolar bulbs (Chen et al., 2007). Under salt stress, the rate of AtPIP2;1 cycling between the PM and the TGN/EE increases as compared to resting conditions ( $\mathrm{Li}$ et al. 2011; Luu et al. 2012). In addition, the phosphorylation status of PIP aquaporins is modified by salt stress and is positively correlated 
to changes in root hydraulic conductivity (Prak et al. 2008; Di Pietro et al. 2013). Indeed, this posttranslational modification was previously shown to regulate PIP aquaporin activity/gating and PM abundance (Johansson et al. 1998; Tornroth-Horsefield et al. 2006; Prak et al. 2008; Van Wilder et al. 2008).

The present work used sunflower plant to examine the expression and regulation profiles of some aquaporins, their role in regulating water transport during salt stress and their role in improving plant tolerance to stresses.

\section{Materials and methods}

\section{Plant material}

Seeds of Sunflower (Helianthus annuus L. cv. Sakha-53) accessed from the Field Research Institute; Agricultural Research Centre, Giza, Egypt

\section{Experimental field and treatment}

Sunflower seeds were soaked in aerated water for 1 day at $22^{\circ} \mathrm{C}$. Then they were transferred to plastic pots filled with perlite and the pots were kept in 50x50 cm trays containing Ruakura nutrient solution (Smith et al., 1983). The trays were incubated in the green house conditions of the experimental field of Botany Department (Faculty of Science, Damietta University). The climatic conditions over the experiment period were: $27-31 / 22-25^{\circ} \mathrm{C}$ day/night temperature, $65-$ $75 \%$ relative humidity during the day $(\mathrm{RH}), 12-13$ $\mathrm{h}$ photoperiod and 2,850 $\mu$ mole $\mathrm{m}^{-2} \mathrm{~s}^{-1}$ maximum light intensity (full sunlight). Each pot contained 4 seeds that were thinned to one seedling per pot when the plants were 8 days old.

At the age of two weeks, the seedlings were exposed to salt stress. The plants were categeroized into five groups as follows: the control group that was watered with Ruakura nutrient solution every two days, the second and third groups were treated with 25 and $150 \mathrm{mM}$ $\mathrm{NaCl}$, respectively and the fourth and fifth ones were treated with 25 and $150 \mathrm{mM} \mathrm{KCl}$, respectively. The concentration of $150 \mathrm{mM} \mathrm{NaCl}$ and $\mathrm{KCl}$ was applied gradually starting from 25 $\mathrm{mM}$ and $50 \mathrm{mM}$ increment every day until reaching the final concentration.

\section{Measurement of Photosynthetic rate (A)}

Photosynthetic rate was measured for the second leaves in the control and treated intact plants by using LCi-SD gas exchange system (Analytical Development Company, ADC Ltd, Hertfordshire, UK) after 9 days of the treatments. The measurements were made at five different time periods during the day $(9: 00,11: 00,13: 00,15: 00$ and 17:00).

\section{Determination of fresh and dry weights, water contents $(W C)$}

The plants materials were harvested after 10 days of the treatment onset. After recording the fresh weights $(\mathrm{FW})$ of leaf, root, stem, they were dried in oven at $80^{\circ} \mathrm{C}$ for 2 days and the dry weights (DW) were recorded. Five plant replicates were used for each treatment. The water content (WC) of the leaves and petiols samples were collected at $(5: 00,9: 00,11: 00,13: 00,15: 00,17: 00)$ and calculated as follows: Water content $(\mathrm{WC} \%)=$ $(\mathrm{FW}-\mathrm{DW}) / \mathrm{FW} \times 100$

\section{Harvesting of the plant material}

For each treatment, samples from the second top leaf were collected and frozen immediately in liquid nitrogen after $10 \mathrm{~d}$ of the treatment and stored in $-80^{\circ} \mathrm{C}$ for the subsequent analyses. Five replicates were collected at $(9: 00,13: 00,17: 00)$.

\section{Quantification of aquaporin genes expression}

Total RNA from $50 \mathrm{mg}$ frozen leaves was extracted using (Quick- RNA Miniprep) kit, according to the manufacturer's instructions with some modification: $10 \%$ polyvinylpyrrolidone (Fischer Scientific, Belgium) was added to the extraction buffer and then after extraction and for further purification, RNA was re-suspended in ethanol and re-washed by the washing buffer provided within the kit. Semi quantitative RTPCR was performed by using the primers sets (Table 1). Primers for (PIP1;5, PIP2;1, PIP2;3, $T I P 1 ; 1)$ were designed to recognize the conserved regions resulting from the alignment of the characterized genes from other species found in NCBI and ExPASy databases. The PCR conditions were adjusted as follows: initial denaturation at $95^{\circ} \mathrm{C}$ for $3 \mathrm{~min}$ followed by $35: 40$ cycles of denaturation at $95^{\circ} \mathrm{C}$ for $30 \mathrm{~s}$, annealig at $52: 54^{\circ} \mathrm{C}$ for 30 s and extension at $72^{\circ} \mathrm{C}$ for $1 \mathrm{~min}$. For each gene, the number of PCR cycles was 
optimized to show the maximum differences among samples within the linear phase of amplification. The conditions and cycle numbers were determined to avoid the DNA saturation. The PCR products were resolved on $1 \%$ agarose gels, stained with ethidium bromide $(\mathrm{EtBr})$ in $1 \times \mathrm{TAE}$ buffer (Tris-acetic acid-EDTA) and visualized by
UVIsave gel documentation system (UVITECH, UK). Image Studio v 12.0 software (Li-COR Biosciences, USA) was used to measure the band sizes. The measurements were normalized for equal $18 S$ rRNA. For each aquaporin gene, three replicates from different RNA extractions were used.

Table 1: The forward and reverse primers with annealing temperature and number of cycles used in Semi quantitative RTPCR

\begin{tabular}{|l|l|l|l|l|}
\hline gene & F PRIMER & R PRIMER & $\begin{array}{l}\text { Annealing } \\
\text { temperature(ta) }\end{array}$ & $\begin{array}{l}\text { Number } \\
\text { of cycles }\end{array}$ \\
\hline PIP1;5 & CATGCAGTGCCTGGGCGC & GTGCCGGTGATGGGGATG & 52 & 37 \\
\hline PIP2;1 & GCGCCGCTGATCGACGCG & CACTGCGCCACGATGTAGAG & 54 & 40 \\
\hline PIP2;3 & GGCATCTCAGGTGGGCAC & GCCAACACCGGGACGTGGG & 54 & 40 \\
\hline TIP1;1 & AGCCACCAGGAGGTGTAC & ACGAAGGCGCCGAAGGTC & 52 & 40 \\
\hline
\end{tabular}

\section{Statistical analysis}

Two-way ANOVA analyses with Fisher's least significant way difference (LSD) post hoc test were performed using SigmaPlot $\mathrm{v} 11.0$ at significant level of $P \leq 0.05$.

\section{Results}

The effect of salt stress on fresh weight $(F W)$ and Dry weight $(D W)$

Shoot fresh weight (FW) of $H$. annuus L. was significantly affected by different concentrations of salt treatment (Fig. 1, Fig. 2 A). There were no significant difference in the reduction of the shoot $\mathrm{FW}$ of Both $25 \mathrm{mM}$ concentrations of $\mathrm{Na}^{+}$and $\mathrm{K}^{++}$. But at $150 \mathrm{mM}$ of salt treatment, $\mathrm{K}^{++}$showed the lowest FW of the shoot when compared with $\mathrm{Na}^{+}$ as it was about $24.6 \%$ of the control. Generally the same trend was shown in the shoot dry weight (DW) as the control plants showed the highest value of shoot DW (Fig. 2 B). There was no significant difference between the shoot DW at 25 $\mathrm{mM}$ of both types of salts. The difference was shown at $150 \mathrm{mM}$ as the $\mathrm{K}^{++}$ions significantly caused a reduction in the DW of the shoot more than the reduction caused by $\mathrm{Na}^{+}$ions.

The results of the root FW differed completely from that of shoot. As the highest value was recorded for the plants treated with $25 \mathrm{mM} \mathrm{KCl}$, then the values for control and $25 \mathrm{mM} \mathrm{Na}$ treated plants that showed almost equal values (Fig. $3 \mathrm{~A}$ ). The most significant decrease in the root $\mathrm{FW}$ was shown by the plants treated with $150 \mathrm{mM}$ salts which reduced to be $61.7 \%$ of the control. Contrarily, the highest DW for the roots recorded was for the control and the treated plants with 25 $\mathrm{mM} \mathrm{Na}{ }^{+}$(Fig. 3 B). There were no significant difference in the root DW of the plants treated with $150 \mathrm{mM} \mathrm{Na}$ and those of the same concentration of $\mathrm{K}^{+}$, recording the lowest value of the root DW.

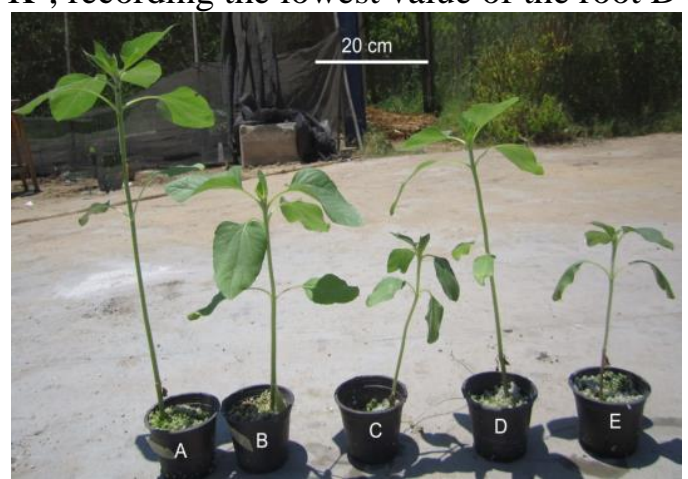

Fig. 1. Growth of $H$. annuus L. after $10 \mathrm{~d}$ in the green house; control (A) or salt conditions (B: $25 \mathrm{mM} \mathrm{NaCl}, \mathrm{C}: 150 \mathrm{mM}$ $\mathrm{NaCl}$, D: $25 \mathrm{mM} \mathrm{KCl}, \mathrm{E}: 150 \mathrm{mM} \mathrm{KCl}$ ). A scale bar of $20 \mathrm{~cm}$ is shown.

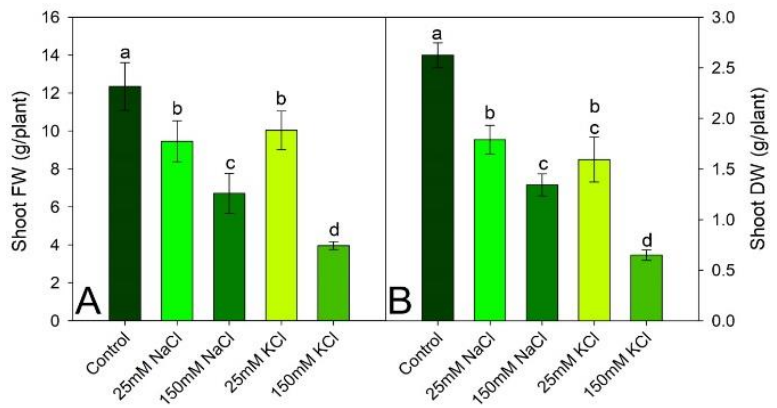

Fig. 2. Effect of salt treatment on the growth of H. annuus L. in terms of shoot fresh weight and dry weight (A, B) respectively. Bars are means of 5 replicates \pm SE. Bars \pm SE labeled with different small letters are significantly different at $p<.05$. 


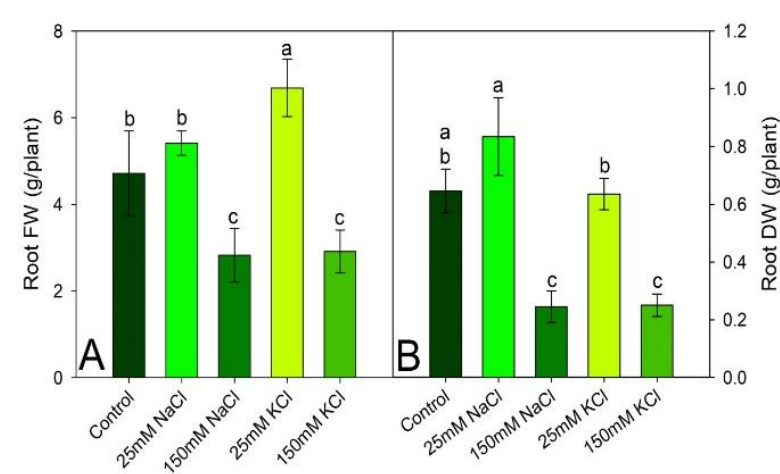

Fig. 3. Effect of different salt treatments on the growth of $H$. annuus L. in terms of root fresh weight and dry weight (A, B) respectively. Bars are means of 5 replicates \pm SE. Bars \pm SE labeled with different small letters are significantly different at $p<.05$.

\section{The effect of salt treatment on water contents $(W C)$}

WC of the control leaves (Fig. 4 A) decreased slightly at 13:00 compared to 9:00. Similarly, the WC of leaves decreased gradually during the day to reach the minimum value at 13:00 then increased again at 17:00. The decrease in WC for the leaves of $150 \mathrm{mM} \mathrm{NaCl}$ stress was slight but significant at 13:00 compared to 9:00 to be $90 \%$ of that at 9:00. Similarly, both 25 and $150 \mathrm{mM} \mathrm{KCl}$ stressed leaves showed a decrease at 13:00 in its WC compared to 9:00. The leaf WC significantly decreased for all salt treatments compared to the control at all-time points.

A gradual decrease in petiole $\mathrm{WC}$ was observed during the day in the control plants (Fig. 4 B) to be $87.4 \%$ at 13:00 of that at 9:00. This value increased again at 15:00. Similarly, $25 \mathrm{mM} \mathrm{NaCl}$ treated plants showed a significant decrease in their petiole WC at 13:00 compared to that at 9:00 but followed by an increase in this value at 17:00. A similar trend to control plants was shown by 150 $\mathrm{mM} \mathrm{NaCl}$ treated plants and $25 \mathrm{mM} \mathrm{KCl}$ treated plants. $150 \mathrm{mM} \mathrm{KCl}$ treated plants had a different pattern where their petiole WC increased at 11:00 from that at 9:00 followed by a decrease at 13:00 to be $89.2 \%$ of that at 9:00.

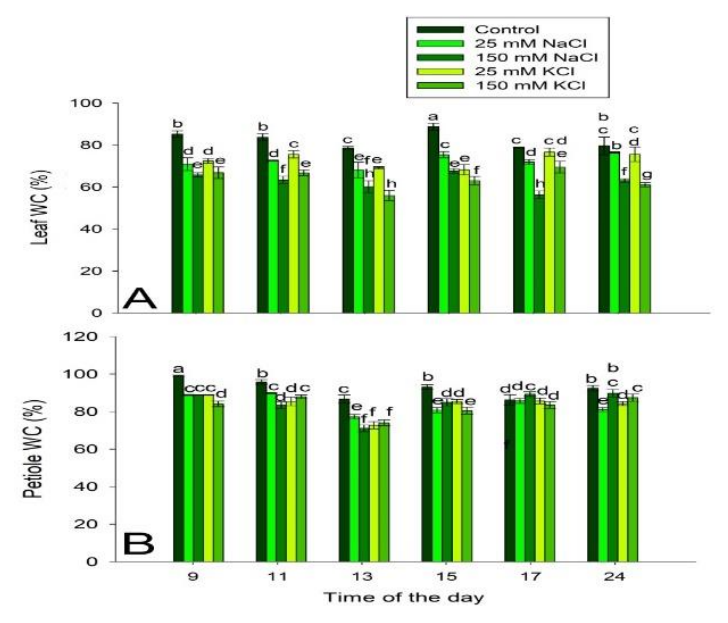

Fig. 4. Effect of salt treatment on the leaf WC (A) and petiole WC (B) of $H$. annuus L. Bars are means of 5 replicates \pm SE. Bars \pm SE labeled with different small letters are significantly different at $p<.05$.

\section{The effect of salt treatment on Photosynthetic rate (A)}

Generally, photosynthetic rate value decrease from 9:00 to 11:00 and the value is fixed at the mid-day (11:0 till 13:00). The depression was shown again at 15:00 and 17:00. (Fig. 5).

When comparing the control plants with the salt stressed ones, generally photosynthetic rate reduced in response to different salt treatments at all the time points except for the treatment with 25 $\mathrm{mM} \mathrm{KCl}$, it showed similar value of the photosynthesis with the control at 9:00, 13:00 and 17:00 but even higher value at 11:00. The reduction in photosynthetic rate occurred only at 15:00 to be $92.4 \%$ of the control at this time. Generally, the treatment of $150 \mathrm{mM}$ of both salts resulted in the maximum reduction in photosynthetic rate at all-time points.

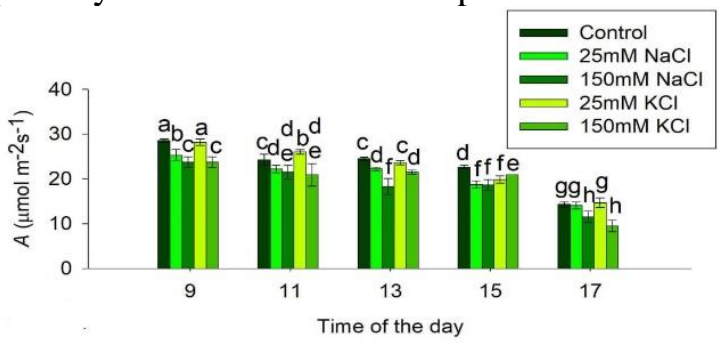

Fig. 5. Changes in photosynthetic rate during the day in $H$. annuиs L. in response to different salt treatments. Bars are means of 5 replicates \pm SE. Bars \pm SE labeled with different small letters are significantly different at $p<.05$. 
Responses of aquaporin expression to salt stress

\section{PIP1; 5 expression in leaf of $H$. annuus $L$.}

The expression of PIP1;5 in the leaves of the control plants showed a gradual depression during the day till it reach its minimum level at 17:00 (Fig. 6). Contrarily, the expression of this gene in the plants treated with $25 \mathrm{mM} \mathrm{NaCl}$ increased significantly at 13:00 followed by a significant decrease at 17:00 to be $53.3 \%$ of that at 13:00 then a significant increase were observed at 24:00. For the plants treated with $150 \mathrm{~m} \mathrm{M} \mathrm{NaCl}$, the expression of this gene in their leaves increased progressively during the day, the maximum level of the expression was recorded at 17:00 but this level decreased significantly at 24:00. Generally, the expression of this gene in the sets treated with $\mathrm{NaCl}$ was higher than that of the control sets except at 9:00 when the expression in the control set was higher. The set which treated with the low concentration of $\mathrm{KCl}$ showed the same level of expression of this gene at 9:00 and 13:00 but this expression decreased at 17:00 to be $66.4 \%$ of that at 13:00, followed by a significant increase at 24:00. Contrarily, the application of higher concentration of $\mathrm{KCl}$ resulted in a significant increase in the expression of PIP 1,5 in the leaves of these plants at 13:00 and 17:00 to be higher than that for the control plants.

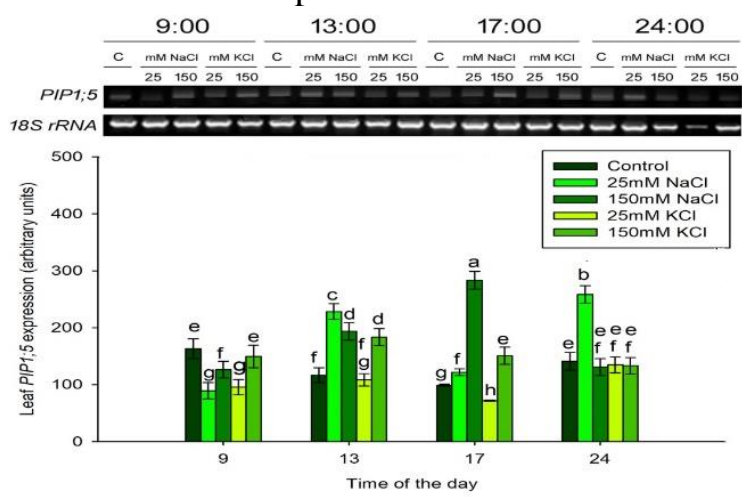

Fig. 6. Changes in the expression of PIP1;5 in leaf of $H$. annuus L. after different salt treatments. Bars are means of 3 replicates $\pm S E$. Bars \pm SE labeled with different small letters are significantly different at $p<.05$.

PIP2; 1 expression in leaf of $H$. annuus $L$. The expression of PIP 2;1 in the leaves of the control plants significantly increased at 13:00 compared to 9:00, followed by a decrease in the expression level to be undetectable at 17:00 (Fig. 7). Contrarily, the expression of this gene gradually increased during the day in the leaves of plants treated with $25 \mathrm{mM} \mathrm{NaCl}$ but no gene expression was observed at 24:00. The leaves of the plants treated with high concentration of $\mathrm{NaCl}$ showed a significantly higher gene expression at 9:00 and 17:00, but the expression was not detectable for these plants at 13:00 and 24:00. The expression of PIP2;1 in the leaves of the plants treated with both low and high concentrations of $\mathrm{KCl}$ was of the same pattern as it was undetectable at 13:00 and 24:00 for the two sets, but it was higher than that of the control plants at 9:00 and 17:00.

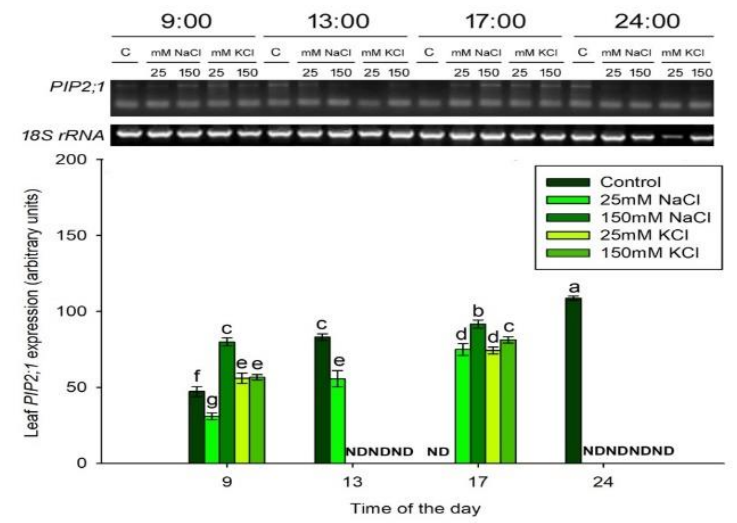

Fig. 7. Changes in the expression of PIP2;1 in leaf of $H$. annuus L. after different salt treatments. Bars are means of 3 replicates \pm SE. Bars \pm SE labeled with different small letters are significantly different at $p<.05$.

\section{PIP2;3 expression in leaf of $H$. annuus $L$.}

A significant increase in the expression of PIP2;3 in the leaves of the control plants at 13:00 which record the highest expression during the day for all the treatments (Fig. 8), followed by a significant decrease in the expression level at 17:00 to be $24.6 \%$ of that at 13:00. The same pattern of expression was observed in the plants treated with low concentration of $\mathrm{NaCl}$ but the difference is that the expression of this gene in the former set was much lower than of the latter one. Contrarily, the expression for the plants treated with the high concentration of $\mathrm{NaCl}$ was of the same level as that for the control plants at almost all time points, except at 17:00 where it was higher for the latter set. The expression pattern for the plants treated with $\mathrm{KCl}$ was completely different from the previous as it significantly decreased at 13:00 but increased again at 17:00 and was not detected at 24:00. The expression for the plants treated with $\mathrm{KCl}$ was lower than that of the control plants at all the time points except at 17:00. 


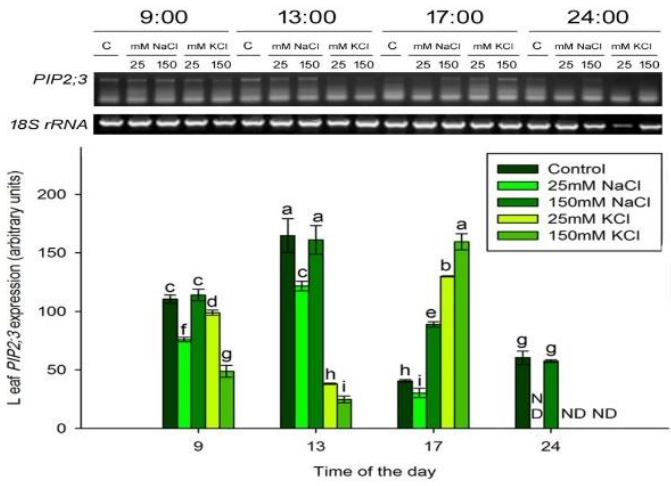

Fig. 8. Changes in the expression of $P I P 2 ; 3$ in leaf of $H$. annuus L. after different salt treatments. Bars are means of 3 replicates \pm SE. Bars \pm SE labeled with different small letters are significantly different at $p<.05$.

\section{TIP1;1 expression in leaf of $H$. annuus $L$.}

TIP1;1 expression in the leaves of the control plants showed a gradual increase in its expression during the day to record the highest level of expression at 24:00 (Fig. 9). The same trend was shown by the expression of this gene in the leaves of $25 \mathrm{mM} \mathrm{NaCl}$ set except that the expression lowered at $24: 00$ to be $43.6 \%$ of the control at this time. For $150 \mathrm{mM} \mathrm{NaCl}$ set, the expression of this gene increased significantly at 13:00 compared to 9:00 and to be higher than that in the control plants, followed by a decrease at 17:00 which remained the same level of expression until 24:00. The expression of TIP1;1 was the highest at 9:00 and 24:00 in the leaves of $25 \mathrm{mM} \mathrm{KCl}$ treated set, but decreased at 13:00 and 17:00. The same trend was shown by the plants treated with the higher concentration of $\mathrm{KCl}$ except it was higher in the latter set.

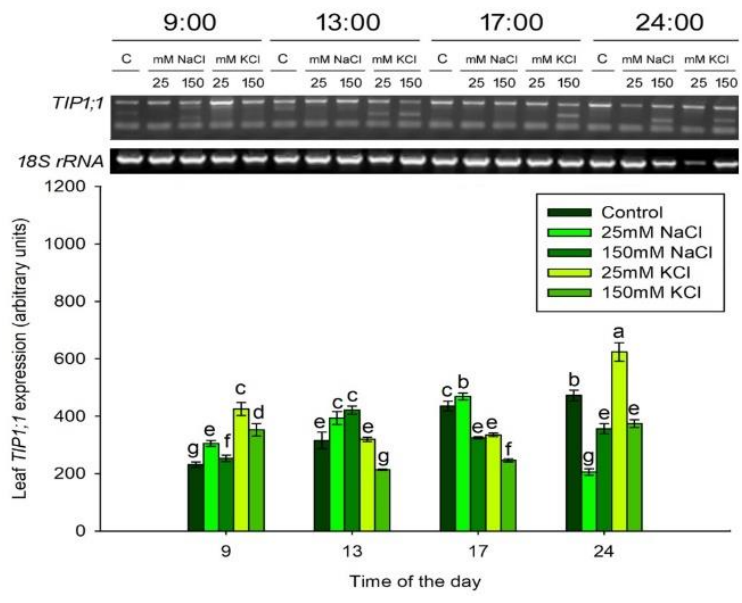

Fig. 9. Changes in the expression of $T I P 1 ; 1$ in leaf (A) and root (B) of $H$. annuus L. after drought treatment. Bars are means of 3 replicates \pm SE. Bars \pm SE labeled with different small letters are significantly different at $p<.05$.

\section{Discussion}

One of the major environmental stresses, which restrict plant growth, is salinity (Mahajan and Tuteja 2005). Figure 1 and 2 showed the difference in the growth between the control plants that was the highest in the growth rate and shoot FW, DW and the salt stressed ones. Contrarily the salt stressed plants showed a depression in the growth. For a moderate salinity stress, an inhibition of lateral shoot development becomes apparent over weeks and over months there are effects on reproductive development, such as early flowering or a reduced number of florets. During this time, a number of older leaves may die. However, production of younger leaves continues. All these changes in plant growth are responses to the osmotic effect of the salt, and are similar to drought responses (Munns and Tester, 2008). Our results showed that the higher the concentration of the salt, the lower the growth appeared. As high salt concentration also causes ion toxicity, nutritional disorders and oxidative stress which result in alteration of major physiological processes, such as photosynthesis, cell division and elongation, maintenance of membrane integrity, protein synthesis as well as energy and lipid metabolism (Hilal et al., 1998). Together, these effects reduce plant growth, development and yield. Contrarily, the root FW and DW showed a different results where the higher FW was recorded for $25 \mathrm{mM} \mathrm{KCl}$ treated plants and the higher DW for $25 \mathrm{mM} \mathrm{NaCl}$ (Fig. 3 ). This could be explained by the less affected root growth than leaf growth, and root elongation rate recovers remarkably well after exposure to $\mathrm{NaCl}$ or other osmotica (Munns, 2002).

Initial exposure to salinity immediately triggers an osmotic stress as high salt concentration in the soil decreases the soil water potential. WC directly reflects the water status of plants and its reduction indicates that salinity resulted in water deficit in plants. Thus our results showed a depression in WC of the leaves and petioles of the salt stressed plants (Fig. 4). Along with our results Yang et al. (2009) and Jiang et al. (2014)_indicated that the negative effect on plant water relations was induced by an increase in soluble salts which decelerate the uptake of water and nutrients causing osmotic effects and toxicity. Also the pattern of leaf WC during the day for both control and the treated plants showed a depression at midday due to the high temperature and VPD.

Although sunflower is classified as one of the most salt-tolerant types of plants and is considered 
as a pioneer plant in the reclamation of saline soils, its growth and photosynthetic rate are negatively affected by high salt levels in soil (Vasilakoglou et al., 2011). Thus our results showed a depression in photosynthetic rate almost along the day for the $\mathrm{NaCl}$ stressed plants compared to the control (Fig. 5). It is always difficult to know whether a reduced rate of photosynthesis is the cause of a growth reduction, or the result. With the onset of salinity stress, a reduced rate of photosynthesis is certainly not the sole cause of a growth reduction because of the rapidity of the change in leaf expansion rates described earlier (Cramer and Bowman, 1991; Fricke et al., 2004; Passioura and Munns, 2000), and also because of the increase in stored carbohydrate, which indicates unused assimilate (Munns et al., 2000). However, with time, feedback inhibition from sink to source may fine tune the rate of photosynthesis to match the reduced demand arising from growth inhibition (Paul and Foyer, 2001). Also at high salinity, salts can build up in leaves to excessive levels. Exactly how the salts exert their toxicity remains unknown. Salts may build up in the apoplast and dehydrate the cell, they may build up in the cytoplasm and inhibit enzymes involved in carbohydrate metabolism, or they may build up in the chloroplast and exert a direct toxic effect on photosynthetic processes.

Besides the osmotic effect, high salt concentration also causes ion toxicity, nutritional disorders and oxidative stress which result in alteration of major physiological processes, such as photosynthesis, cell division and elongation, maintenance of membrane integrity, protein synthesis as well as energy and lipid metabolism (Hilal et al. 1998). Although sunflower plants were found to have high yield with high $\mathrm{K}^{+}$levels than plants with low $\mathrm{K}^{+}$supply (Soleimanzadeh et al. 2010a) but our results showed that the leaves treated with $150 \mathrm{mM} \mathrm{NaCl}$ or $\mathrm{KCl}$ caused a reduction in photosynthetic rate when compared with their corresponding controls. This could be explained by the lack of a retranslocation system due to the high potassium concentrations (> 200 $\mathrm{mM} \mathrm{KCl)} \mathrm{which} \mathrm{accumulate} \mathrm{in} \mathrm{the} \mathrm{leaves} \mathrm{as} \mathrm{a}$ consequence of high transpiration rates (Smith and Stewart 1990). But the diurnal physiological behavior of both ions was quite different as the accumulation of $\mathrm{Na}^{+}$ions resulted in a further decrease in photosynthetic rate at 13:00 than 9:00 and compared to that in leaves treated with 150 $\mathrm{mM} \mathrm{KCl}$, suggesting that sunflower was more sensitive to $\mathrm{NaCl}$ than $\mathrm{KCl}$ treatment. As $\mathrm{K}^{+}$ promotes enzyme activity, which contributes to carbohydrate, protein and fat metabolism of sunflower (Tisdale et al. 1985). This also could explain the high or even equal $A$ in $25 \mathrm{mM} \mathrm{KCl}$ treated plants during the day compared to their control while $25 \mathrm{mM} \mathrm{NaCl}$-treated plants showed the reverse.

Understanding the role of aquaporins in this context now requires integration of numerous observations made at the molecular, cell, and tissue levels. $25 \mathrm{mM} \mathrm{NaCl}$ treatment induced high expression of PIP1;5 and TIP1;1 at 13:00 which may be required for improving the hydraulic conductivity (Fig. 6 and 9). Although MartinezBallesta et al. (2003) showed that exposure of Arabidopsis plants to salt (up to $100 \mathrm{mM}$ ) induces a general transcriptional down-regulation of PIPs, our results showed also high expression of $P I P 1 ; 5$ and TIP1;1 for $150 \mathrm{mM} \mathrm{NaCl}$-treated plants at 13:00 when compared with their corresponding controls. Where as Heinen et al., (2014) suggested that PIP1;5 has a role in $\mathrm{CO}_{2}$ transport in the leaves. Our results indicated that the expression pattern in the control leaves was higher at 9:00 compared to 13:00 where the $A$ was highest. This suggests that $P I P 1 ; 5$ has role in $\mathrm{CO}_{2}$ transport.

The expression of PIP2; 1 (Fig. 7) was upregulated at 9:00 and 17:00 for $150 \mathrm{mM} \mathrm{NaCl}$ stressed leaves and $\mathrm{KCl}$ treated plants compared to their control. This expression pattern walked with the finding that transcript and protein levels of the barley HvPIP2; 1 gene were down-regulated in roots but up-regulated in the shoots of plants under salt stress (Katsuhara et al., 2002).

Our results showed high expression level of PIP2;3 at 13:00 compared to 9:00 for the control and $\mathrm{NaCl}$ stressed plants (Fig. 8). Meanwhile many reports have shown that PIP2;3 have high water transport activity. Daniels et al. (1994) and Johanson et al. (2001) reported high water permeability in oocytes expressing AtPIP2;3 (Arabidopsis thaliana) (RD28).Thus this gene might have role in mesophyll conductance.

Along with our results, the differential regulation of aquaporins might contribute to increased resistance/susceptibility to a specific stress, in a species-specific way. aquaporins fine regulation helps plants maintain a positive water balance under detrimental environmental conditions. Both down- and up-regulation of aquaporin expression leading to changes in membrane permeability have been described and proposed to be beneficial for plants experiencing water deficit. There are different hypotheses explains mechanisms. On one hand, plants may decrease the water permeability of their cell membranes to avoid 
excessive loss of water from the root to the soil (Martinez-Ballesta et al., 2003; Aroca et al., 2006). On the other hand, aquaporins might play a role in stress avoidance by enhancing root water uptake, when the water potential gradient between soil and root xylem is still favorable (Lian et al., 2004; Hachez et al., 2012). The contribution of both types of responses may depend on the plant species, the intensity and duration of the stress and aquaporin isoform (Bogeat-Triboulot et al., 2007; Galmes et al., 2007; Qian et al., 2015).

The salt tolerance is a complex trait but might be partly due to the expression of stress-inducible aquaporin isoforms (Chang et al., 2016; Yamamoto et al., 2015). Studies in Hordeum vulgare (barley) leaves suggest that increased abundance of $H v P I P 1 ; 6$ transcripts in response to salt may reflect a role for this aquaporin in promoting residual growth of the leaf under stress (Fricke et al., 2006).

\section{Conclusion}

Soil salinity had an adverse effect on the growth and photosynthetic activity of plants. Plant water status depends on efficient water supply at the root level and distribution through the plant body. Recent research on aquaporins has confirmed their crucial role in plant water relations. Given that expression of some aquaporins may improve overall tolerance to drought or salt stress, these aquaporins isoforms could be identified and selected for via breeding programs or engineered in crop species to confer improved salt stress tolerance. However, it appears that the mechanisms regulating plant stress are highly complex and involved various interconnected hormonal and hydraulic signals that lead to regulation of cell and tissue permeability through modifications of aquaporin expression, trafficking, and activity. Much remains to be discovered about the function and regulation of aquaporins during salt stress. Understanding the role of aquaporins requires integration of numerous observations made at the molecular, cell, and tissue levels. Fundamental regulation properties that explain the remarkable ability of plant cells to withstand osmotic stress have emerged from basic knowledge of plant cell water relations and from more recent research on aquaporins.

\section{References}

Alexandersson E, Danielson JA, Rade J, Moparthi VK, Fontes M, Kjellbom P, Johanson U (2010) Transcriptional regulation of aquaporins in accessions of Arabidopsis in response to drought stress. Plant J 61:650-660.

Alexandersson E, Fraysse L, Sjövall-Larsen S, Gustavsson S, Fellert M, Karlsson M, Johanson U, Kjellbom P (2005) Whole gene family expression and drought stress regulation of aquaporins. Plant Mol Biol 59:469-484.

Aroca R, Ferrante A, Vernieri P, Chrispeels MJ (2006) Drought, Abscisic Acid and Transpiration Rate Effects on the Regulation of PIP Aquaporin Gene Expression and Abundance in Phaseolus vulgaris Plants. Ann Bot 98(6): 1301-1310.

Bienert GP, Chaumont F (2013) Aquaporin-facilitated transmembrane diffusion of hydrogen peroxide. Biochim Biophys Acta 1840(5):1596-604.

Bogeat-Triboulot MB1, Brosché M, Renaut J, Jouve L, Le Thiec D, Fayyaz P, Vinocur B, Witters E, Laukens K, Teichmann T, Altman A, Hausman JF, Polle A, Kangasjärvi J, Dreyer E (2007 ) Gradual soil water depletion results in reversible changes of gene expression, protein profiles, ecophysiology, and growth performance in Populus euphratica, a poplar growing in arid regions. Plant Physiol 143(2):876-92.

Bohnert HJ, Jensen RG. (1996) Metabolic engineering for increased salt tolerance, the next step. Aust J Plant Physiol 23:661-666.

Boursiac Y, Boudet J, Postaire O, Luu DT, TournaireRoux C, Maurel C (2008) Stimulus-induced downregulation of root water transport involves reactive oxygen species-activated cell signaling and plasma membrane intrinsic protein internalization. Plant J 56:207-218.

Boursiac Y, Chen S, Luu DT, Sorieul M, van den Dries N, Maurel C (2005) Early effects of salinity on water transport in Arabidopsis roots. Molecular and cellular features of aquaporin expression. Plant Physiol 139:790-805.

Bressan A, Semetey O, Nusillard B, Clair D, BoudonPadieu E (2008) Insect vectors (Hemiptera: cixiidae) and pathogens associated with the disease syndrome 'basses richesses' of sugar beet in France. Plant Disease 92:113-119.

Chang W, Liu X, Zhu J, Fan W, Zhang Z (2016) An aquaporin gene from halophyte Sesuvium portulacastrum, SpAQP1, increases salt tolerance in transgenic tobacco. Plant Cell Rep 35:385-395.

Chaumont F, Tyerman SD (2015) Aquaporins: Highly Regulated Channels Controlling Plant Water Relations. Plant Physiol 164: 1600-1618.

Chen H, An R, Tang J-H, Cui X-H, Hao F-S, et al. (2007) Over-expression of a vacuolar $\mathrm{Na}+\mathrm{H}+$ 
antiporter gene improves salt tolerance in an upland rice. Mol Breed 19:215-25.

Cramer GR (2002) Response of abscisic acid mutants of Arabidopsis to salinity. Funct. Plant Biol. 29:561-67.

Cramer GR, Bowman DC (1991) Kinetics of maize leaf elongation. I. Increased yield threshold limits shortterm, steady-state elongation rates after exposure to salinity. J. Exp. Bot. 42:1417-26.

Daniels MJ, Mirkov TE, Chrispeels MJ (1994) The plasma membrane of Arabidopsis thaliana contains a mercury-insensitive aquaporin that is a homolog of the tonoplast water channel protein TIP. Plant Physiol 106: 1325-1333.

Di Pietro M, Vialaret J, Li GW, Hem S, Prado K, Rossignol M, Maurel C, Santoni V (2013) Coordinated post-translational responses of aquaporins to abiotic and nutritional stimuli in Arabidopsis roots. Mol Cell Proteomics 12:38863897.

Fricke W, Akhiyarova G, Veselov D, Kudoyarova G (2004) Rapid and tissue-specific changes in ABA and in growth rate response to salinity in barley leaves. J Exp Bot 55:1115-23.

Fricke W, Akhiyarova G, Wei W, Alexandersson E, Miller A, et al. (2006) The short-term growth response to salt of the developing barley leaf. J Exp Bot 57:1079-95.

Fricke W, Peters WS (2002) The biophysics of leaf growth in salt-stressed barley. A study at the cell level. Plant Physiol 129: 374-88.

Galmes J, Pou A, Alsina M, Tomas M, Medrano H, Flexas J (2007) Aquaporin expression in response to different water stress intensities and recovery in Richter-110 (Vitis sp.): relationship with ecophysiological status. Planta 226:671-681.

Gilliham M, Tester M (2005) The regulation of anion loading to the maize root xylem. Plant Physiol 137: 819-28.

Gomes D, Agasse A, Thiébaud P, Delrot S, Gerós H, Chaumont F (2009) Aquaporins are multifunctional water and solute transporters highly divergent in living organisms. Biochim Biophys Acta 1788: 1213-1228.

Hachez C, Chaumont F (2010) Aquaporins: a family of highly regulated multifunctional channels. Adv Exp Med Biol 679: 1-17.

Hachez C, Laloux T, Reinhardt H, Cavez D, Degand H, Grefen C, De Rycke R, Inze D, Blatt MR, Russinova E, Chaumont F (2014a) Arabidopsis SNAREs SYP61 and SYP121 coordinate the trafficking of plasma membrane aquaporin PIP2;7 to modulate the cell membrane water permeability. Plant Cell 26:3132-3147.

Hachez C, Veselov D, Ye Q, Reinhardt H, Knipfer T, Fricke W, Chaumont F (2012) Short-term control of maize cell and root water permeability through plasma membrane aquaporin isoforms. Plant Cell Environ 35:185-198.

Hachez C, Veselov D, Ye Q, Reinhardt H, Knipfer T, Fricke W, Chaumont F (2012) Shortterm control of maize cell and root water permeability through plasma membrane aquaporin isoforms. Plant Cell Environ 35: 185-198.

Hachez C, Zelazny E, Chaumont F (2006b) Modulating the expression of aquaporin genes in planta: a key to understand their physiological functions? Biochim Biophys Acta 1758: 1142-1156.

Hasegawa PM, Bressan RA, Zhu JK, Bohnert HJ (2000) Plant cellular and molecular responses to high salinity. Annu Rev Plant Physiol Plant Mol Biol 51:463-99.

Heinen RB, Bienert GP, Cohen D, Chevalier AS, Uehlein N, Hachez C, Kaldenhoff R, Le Thiec D, Chaumont F(2014) Expression and characterization of plasma membrane aquaporins in stomatal complexes of Zea mays. Plant Mol Biol 86(3):33550.

Hilal M, Zenoff AM, Ponessa G, Moreno H, Massa EM (1998) Saline stress alters the temporal patterns of xylem differentiation and alternative oxidase expression in developing soybean roots. Plant Physiol 117:695-701.

Jang JY, Kim DG, Kim YO, Kim JS, Kang H (2004) An expression analysis of a gene family encoding plasma membrane aquaporins in response to abiotic stresses in Arabidopsis thaliana. Plant Mol Biol 54:713-725.

Jiang W, Chen SY, Wang H, Li DZ, Wiens JJ (2014) Should genes with missing data be excluded from phylogenetic analyses? Mol Phylogenet Evol 80:308-18.

Johanson U, Karlsson M, Johansson I, Gustavsson S, Sjovall S, et al. (2001) The complete set of genes encoding major intrinsic proteins in Arabidopsis provides a framework for a new nomenclature for major intrinsic proteins in plants. Plant Physiol. 126:1358-69.

Johansson I, Karlsson M, Shukla VK, Chrispeels MJ, Larsson C, Kjellbom P (1998) Water transport activity of the plasma membrane aquaporin PM28A is regulated by phosphorylation. Plant Cell 10:451459.

Kaldenhoff R, Kai L, Uehlein N (2013) Aquaporins and membrane diffusion of $\mathrm{CO}_{2}$ in living organisms. Biochim Biophys Acta. http:// dx.10.1016/j.bbagen.2013.09.037..

Katsuhara M , Akiyama Y, Koshio K , Shibasaka M , Kasamo K (2002) Functional analysis of water channels in barley roots. Plant Cell Physiol 43 (8): 885-93.

Kilian J, Whitehead D, Horak J, Wanke D, Weinl S, Batistic O, D'Angelo C, Bornberg-Bauer E, Kudla J, Harter K (2007) The AtGenExpress global stress 
expression data set: protocols, evaluation and model data analysis of UV-B light, drought and cold stress responses. Plant J 50:347-363.

Lee SH, Zwiazek JJ (2015) Regulation of aquaporinmediated water transport in Arabidopsis roots exposed to $\mathrm{NaCl}$. Plant Cell Physiol 56:750-758.

Li X, Wang X, Yang Y, Li R, He Q, Fang X, Luu DT, Maurel C, Lin J (2011) Single-molecule analysis of PIP2;1 dynamics and partitioning reveals multiple modes of Arabidopsis plasma membrane aquaporin regulation. Plant Cell 23:3780-3797.

Lian HL, Yu X, Ye Q, Ding X-S, Kitagawa Y, Kwak S-S, et al (2004) The role of aquaporin RWC3 in drought avoidance in rice. Plant and Cell Physiology 45: 481-489.

Lichtenthaler HK (1996) Vegetation Stress: an Introduction to the Stress Concept in Plants. J Plant Physiol 148: 4-14.

Luu DT, Martiniere A, Sorieul M, Runions J, Maurel C (2012) Fluorescence recovery after photobleaching reveals high cycling dynamics of plasma membrane aquaporins in Arabidopsis roots under salt stress. Plant J 69:894-905.

Ma JF (2010) Silicon transporters in higher plants. Adv Exp Med Biol 679: 99-109.

Mahajan S, Tuteja N (2005) Cold, salinity and drought stresses: an overview. Arch Biochem Biophys 444: 139-158.

Martinez-Ballesta MC, Aparicio F, Pallas V, Martinez V, Carvajal M (2003) Influence of saline stress on root hydraulic conductance and PIP expression in Arabidopsis. J Plant Physiol 160:689-697.

Maurel C, Verdoucq L, Luu DT, Santoni V (2008) Plant aquaporins: membrane channels with multiple integrated functions. Annu Rev Plant Biol 59: 595624.

Miwa K, Fujiwara T (2010) Boron transport in plants: co-ordinated regulation of transporters. Ann Bot (Lond) 105: 1103-1108.

Munns R, Guo J, Passioura JB, Cramer GR (2000) Leaf water status controls day-time but not daily rates of leaf expansion in salt-treated barley. Aust. J. Plant Physiol. 27:949-57.

Munns R, Tester M (2008) Mechanisms of salinity tolerance. Ann Rev Plant Biol 59: 651-81.

Munns R. 2002. Comparative physiology of salt and water stress. Plant Cell Environ 25:239-50.

Passioura JB, Munns R. 2000. Rapid environmental changes that affect leaf water status induce transient surges or pauses in leaf expansion rate. Aust J Plant Physiol 27:941-48.

Paul MJ, Foyer CH. 2001. Sink regulation of photosynthesis. J Exp Bot 52:1383-400.

Pih KT, Kabilan V, Lim JH, Kang SG, Piao HL, Jin JB, Hwang I (1999) Characterization of two new channel protein genes in Arabidopsis. Mol Cells 9:84-90.

Postaire O, Tournaire-Roux C, Grondin A, Boursiac Y, Morillon R, Schaffner AR, Maurel C (2010) A PIP1 aquaporin contributes to hydrostatic pressureinduced water transport in both the root and rosette of Arabidopsis. Plant Physiol 152:1418-1430.

Prado K, Boursiac Y, Tournaire-Roux C, Monneuse JM, Postaire O, Da Ines O, Schaffner AR, Hem S, Santoni V, Maurel C (2013) Regulation of Arabidopsis leaf hydraulics involves lightdependent phosphorylation of aquaporins in veins. Plant Cell 25:1029-1039.

Prak S, Hem S, Boudet J, Viennois G, Sommerer N, Rossignol M, Maurel C, Santoni V (2008) Multiple phosphorylations in the C-terminal tail of plant plasma membrane aquaporins: role in subcellular trafficking of AtPIP2;1 in response to salt stress. Mol Cell Prot 7:1019-1030.

Qian ZJ, Song JJ, Chaumont F, Ye Q (2015) Differential responses of plasma membrane aquaporins in mediating water transport of cucumber seedlings under osmotic and salt stresses. Plant Cell Environ 38:461-473.

Sakurai J, Ishikawa F, Yamaguchi T, Uemura M, Maeshima M (2005) Identification of 33 rice aquaporin genes and analysis of their expression and function. Plant Cell Physiol 46:1568-1577.

Smith DS, Johnston CM, Cornforth IS (1983) Comparison of nutrient solutions for growth of plants in sand culture. New Phytol 94: 537-548.

Smith S, Stewart GR (1990) Effect of Potassium Levels on the Stomatal Behavior of the HemiParasite Striga hermonthica. Plant Physiol 94:14721476.

Soleimanzadeh H, Habibi D, Ardakani M R, Paknejad F, Rejali F. 2010a. Response of sunflower (Helianthus annuus 1.) to drought stress under different potassium levels. World Applied Sciences Journal 8:443-448.

Tester M, Davenport RJ (2003) Na+ transport and Na+ tolerance in higher plants. Ann Bot 91:503-27.

Tisdale SL, Nelson WL, Beaton JD (1985) Soil Fertility and Fertilizers. Macmillan Publication, New York. 249-291.

Tornroth-Horsefield S, Wang Y, Hedfalk K, Johanson U, Karlsson M, Tajkhorshid E, Neutze R, Kjellbom P (2006) Structural mechanism of plant aquaporin gating. Nature 439:688-694.

Tyerman SD, Niemietz CM, Bramley H (2002) Plant aquaporins: multifunctional water and solute channels with expanding roles. Plant Cell Environ 25: 173-194..

Van Wilder V, Miecielica U, Degand H, Derua R, Waelkens E, Chaumont F (2008) Maize plasma membrane aquaporins belonging to the PIP1 and 
PIP2 subgroups are in vivo phosphorylated. Plant Cell Physiol 49:1364-1377.

Vasilakoglou I, Dhima K, Karagiannidis N, Gatsis T (2011) Sweet sorghum productivity for biofuels under increased soil salinity and reduced irrigation. Field Crop Res 120: 38-46.

Winter D, Vinegar B, Nahal H, Ammar R, Wilson GV, Provart NJ (2007) An "Electronic Fluorescent Pictograph" browser for exploring and analyzing large-scale biological data sets. PLoS ONE 2:e718. doi: 10.1371/journal.pone.0000718.

Yamamoto N, Takano $\mathrm{T}$, Tanaka $\mathrm{K}$, Ishige $\mathrm{T}$, Terashima S, Endo C, Kurusu T, Yajima S, Yano K, Tada Y (2015) Comprehensive analysis of transcriptome response to salinity stress in the halophytic turf grass Sporobolus virginicus. Front Plant Sci 6:241.

Yang X, Huang J, Jiang Y, Zhang HS (2009) Cloning and functional identification of two members of the ZIP (Zrt, Irt-like protein) gene family in rice (Oryza sativa L.). Mol Biol Rep 36(2):281-7.

Zhu C, Schraut D, Hartung W, Schäffner AR (2005) Differential responses of maize MIP genes to salt stress and ABA. J Exp Bot 56(2):971-2981.

Zhu J-K, Liu JP, Xiong LM (1998) Genetic analysis of salt tolerance in Arabidopsis: Evidence for a critical role of potassium nutrition. Plant Cell 10:1181-91

\title{
عنوان البحث: دور الأكوابورينات في مقاومة الإجهاد الملحي في نبات دوار الشمس \\ سلوان عبدالحكم "، سامي حسين ربيع'، ريهام محمد ندا'، جابر مختار أبو جادالله' \\ ' ق قسم النبات والميكروبيولوجي - كلية العلوم - جامعة دمياط'
}

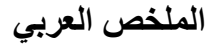

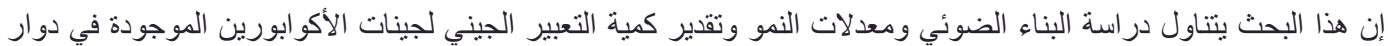

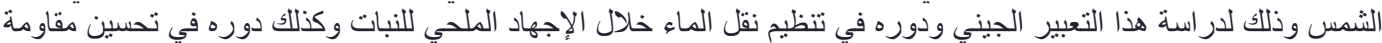

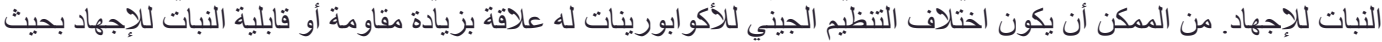

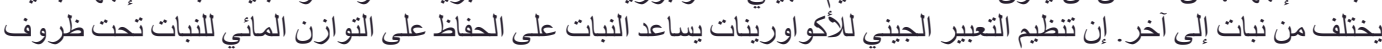

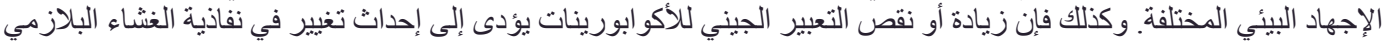

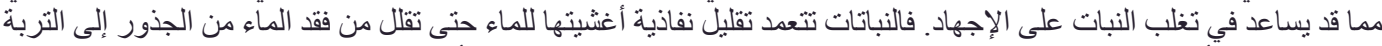

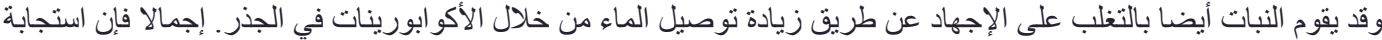

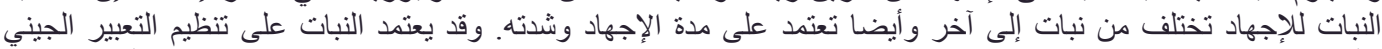

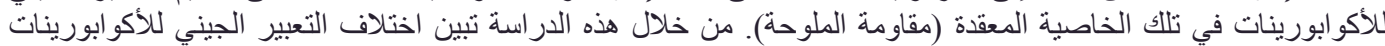
في نبات دوار الثمس و كذلك اختلف نشاط نقل الماء في النباتات التي تعرضت للإجهاد الملحي عن غير ها.
\end{abstract}

